\title{
Foucault: por uma análise pragmática do discurso
}

\author{
Rosane da Conceição Pereira \\ Mestranda em Comunicação, Imagem e Informação \\ UFF
}

\section{Resumo}

Este trabalho apresenta uma abordagem do discurso como prática, com as noções foucaultianas de campo discursivo (dados históricos) e formação discursiva (enunciados de um saber). Concerne igualmente à tematização dos discursos no âmbito das práticas sociais e atos de fala. Elementos inclusos no paralelo possivel entre Análise do Discurso e Pragmática, no que diz respeito à valorização da linguagem em uso e em seu aspecto social. Abrange o rompimento entre essas duas disciplinas, em relação à intenção de comunicar. Culmina, enfim, na definição do que seja uma análise pragmática do discurso, em que a prática discursiva social, em Michel Foucault, malgrado um certo apoio na perspectiva da Pragmática quanto ao uso e ao aspecto social da linguagem, não supõe a intencionalidade consciente do sujeito. O discurso/ ato. como parte da complexidade do processo comunicacional e como é aqui explanado. não pressupõe a expectativa social nem a exclusividade desta esfera. Está submetido ao devir da hisıória. Possui antes o poder de edificar os estados de coisas e os regimes de verdade, que o de representá-los.

\section{Introdução}

"(...) o discurso não é simplesmente aquilo que traduz as lutas ou os sistemas de dominação. mas aquilo por que, pelo que se luta, o poder do qual nos queremos apoderar."

(Michel Foucualt, A ordem do discurso, 1996. p.10) 
O presente trabalho consiste em uma abordagem do discurso em seu caráter de acontecimento, de atividade, sob uma análise pragmática e foucaultiana. Será o esforço de mostrar a linguagem em uso como uma espécie de ato instaurador. Como prática discursiva social que produz e dá suporte aos regimes de verdade, dos quais decorrem as expectativas sociais e os estados de coisas.

A primeira parte da abordagem será dedicada a delimitar o discurso como prática, confrontando a perspectiva da Análise do Discurso com a de Michel Foucault. Procurará apresentar o que o filósofo traz de novo para sua antiga filiação acadêmica, com as noções de campo e formação discursivos. Em seguida, a segunda parte, concernente às práticas sociais e atos de fala, traçará um paralelo entre a Análise do Discurso e a perspectiva da Pragmática, quanto ao uso e ao aspecto social da linguagem, distanciando as duas disciplinas respectivamente da Lingüística e do Positivismo Lógico. Trará, como ponto evidente de divergência entre as duas disciplinas anteriormente associáveis, a intenção de comunicar presente na Pragmática. Por fim, a terceira parte definirá a análise pragmática do discurso, correspondente à tomada do discurso como prática, ou à linguagem em uso como uma espécie de ato produtor. Contudo, será esclarecido que a prática discursiva social, a despeito da contribuição da Pragmática, em Foucault, não supõe a intenção de comunicar consciente do sujeito, uma vez que está submetida ao devir histórico. Nem tampouco pressupõe a esfera social e a primazia desta.

O discurso será então compreendido como aquilo que, muito mais do que documentar ou representar, tem o poder de edificar ou construir.

\section{I - Foucault e a Análise do Discurso: o discurso como prática}

O que é analisar um discurso e como fazê-lo sem incorrer em uma mera análise literária ou numa teoria hermética destacada da realidade? Preocupado com questões nada ingênuas como essa, um grupo de estudiosos franceses começou a pensar a linguagem e a comunicação segundo suas condições de produção, especialmente com os significantes que põem e regem os sentidos, as relações sociais e os sujeitos. Proveniente de um grupo de estudos formado basicamente por Michel Pêcheux, Fany Gadet, Paul Henry e sobretudo Michel Foucault, e inspirada nas teorias de Zellig Harris em 1940-50, a decorrente Análise do Discurso foi considerada politicamente perigosa para sua época (1969), justamente porque se propunha a intervir na esfera social'. Mas o que seria um 
discurso do ponto de vista da Análise do Discurso? Não seria a langue (lingua) nem a parole (fala) estudadas pelo lingüista Saussure. Mais do que um objeto formal restrito a um sistema estruturado por regras internas, o discurso é entendido, todavia, como uma instância de constituição entre a langue e a parole. Não é por menos que Foucault o define como conjuntamente formado pelo caráter lingüístico dos fatos de linguagem, e pelo jogo estratégico e polêmico inerente à história dos domínios de saber relacionados às práticas sociais. Como jogo estratégico e polêmico, o discurso envolve perguntas, respostas, dominações, desvios e conflitos em uma mesma esfera. É através do discurso que os domínios de saber (como a medicina, a escola, a religião, o jornalismo, a publicidade e o cinema) engendram (e são sustentados pelas) práticas sociais (como o tratamento médico, a educação, a catequese, a suposta documentação da verdade, a persuasão para o consumo e a criação de olhares, respectivamente). ${ }^{2}$ De maneira geral, o discurso é então concebido como a linguagem em uso, assumida pelo sujeito que fala, mediante a gênese que a condiciona no mundo.Se acompanharmos Foucault acerca do que é um discurso, podemos dizer que: é um enunciado que só adquire significação no contexto histórico-social e de acordo com o sujeito, aquele que ocupa uma posição vazia na enunciação. Dizer que o sujeito ocupa uma posição vazia é afirmar que ele é um efeito entre interlocutores historicamente assinaláveis, não sendo a fonte a priori do discurso - ilusão do sujeito. Por conseguinte, o sentido do que é enunciado pelo sujeito também é um efeito, não havendo significação por causa de um sujeito (que seria entendido, no caso, como individuo) que interprete, mas conforme as relações de poder que se estabelecem no contexto histórico-social e produzem o saber - ilusão do sentido.

Vale lembrar que ilusão do sujeito e do sentido referem-se a formulações de Michel Pêcheux, analista do discurso, apoiado em Althusser. Para ambos o discurso é um resultado histórico, fabricado, sem causa determinística. De modo que o sujeito é efeito de relações sociais constituidas historicamente, enquanto o sentido é efeito de crenças que instituem verdades. No entanto, Althusser concebe um sujeito ideológico que pode ocupar posições ideológicas diferentes, não necessariamente antagônicas nem contraditórias. Pêcheux, de sua parte, concebe o sujeito como efeito ideológico elementar. ou seja. como aquele que possui a ilusão de ser a fonte do sentido e do discurso na forma de prática politica passando pela ideologia. Por outro lado. Foucault não trabalha com 
as noções de ideologia, sujeito ideológico e sujeito como efeito ideológico elementar. Ao contrário, ele critica parte da tradição acadêmica marxista, aquela ancorada na ideologia como discurso de encobrimento de uma verdade objetiva, como se fosse dada naturalmente. Para Foucault, os textos são sempre vazios de sentido, isto é, as palavras nunca significam em si nem literalmente. Por conseguinte, o sujeito é de discurso ou conhecimento, responsável por ocupar necessariamente uma posição enunciativa em um mundo cujas instituições são constituídas com seus discursos ou enunciados. ${ }^{3} \mathrm{O}$ mérito da Análise do Discurso, diferentemente da Lingüística, consiste em não postular que um sujeito preexistente tem intenção de comunicar algo através de um sistema fechado de signos, a língua. Uma abordagem foucaultiana do discurso mostraria mesmo que ele é construído junto com a linguagem e a comunicação, à medida que gere e sustente relações macro (nucleares; sociais; institucionais) e micro (periféricas; de grupos exclusos; gestos; polissemias; não necessariamente humanas). O discurso como prática social e sua gênese (condições de produção) seriam, então, parte do que Foucault melhor definiu como campo discursivo e formação discursiva. O campo sendo constituído por todos os dados históricos em um certo intervalo de tempo, a formação compreende todos os enunciados que apresentam pontos característicos de um saber, para além da multiplicidade de objetos e autores de tais enunciados em tal período. ${ }^{4}$

\section{II - Análise do Discurso e Pragmática: práticas sociais e atos de fala}

Conceber o discurso como linguagem em uso, assumida pelo sujeito falante na esfera social, incita uma espécie de paralelo entre a Análise do Discurso e a Pragmática. Paralelo que, no entanto, compreende algumas elucidações fundamentais, a fim de eliminar uma aparente confusão entre uma e outra disciplina.

No que diz respeito ao paralelismo sugerido, tanto a Análise do Discurso quanto a Pragmática empreendem o estudo da linguagem em uso em em seu aspecto social. Mas qualquer confusão nesse sentido se dissipa, exatamente, no que se refere às especificidades de cada uma em relação ao uso e ao aspecto social da linguagem.

Em primeiro lugar, em relação ao uso, os integrantes da Análise do Discurso mostraram distanciar-se da Lingüística ao abordarem a linguagem praticada pelo sujeito falante, ao ultrapassarem a visão das línguas 
como objetos formais ou sistemas se signos descolados do mundo. ${ }^{5}$ Os estudiosos da Pragmática. por sua vez. constituiram-na ao tomarem distância do Positivismo Lógico, ou seja, ao tratarem a linguagem como a realização de atos de fala no contexto das linguas. ao desconsiderarem a língua ideal fundada na representação de estados de coisas para a garantia do sentido.

Os membros da Pragmática (Austin e Searle notadamente) tomam a linguagem como a realização de atos e a língua em uso, vinculada ao contexto (linguagem ordinária): enquanto aqueles do Positivismo Lógico (Russell e Frege eminentemente) tomam a linguagem como a representação de estados de coisas e a língua como ideal (logicamente formal), vinculada ao sentido. Particularmente, os estudos de Austin em Pragmática possuem dois momentos fundamentais. No primeiro, ele distingue na linguagem ordinária enunciados chamados performativos (que são atos, como o ato de felicitar: "Felicidades!") e constatativos (que exprimem estados de coisas. como: "O chá está servido."). No segundo. ele admite que todos os enunciados são portadores de uma dimensão performativa para além da puramente constatativa, de modo que haveria três atos em um mesmo enunciado: ato locutório (o que é dito: "A gente estamos estudando uma proposta."). ato ilocutório (o que é realizado ao dizer: a declaração sarcástica da professora Maria Cristina de Morais, presidente da Andes, acerca da greve nas universidades e em alusão ao futuro da educação no pais). e perlocutório (o efeito do que é realizado ao dizer: risos, indiferença. o assentimento ou a discordância dos leitores da revista Veja de 23/12/98. p. 17. em relação ao nada ingênuo descuido vocabular da professora). ${ }^{6}$ Em segundo lugar. em relação ao aspecto social. a Análise do Discurso, especialmente sob uma abordagem foucaultiana, é a tentativa de inscrever a linguagem em uso pelo sujeito (o discurso) não apenas no plano nuclear das instituições sociais. mas também no plano periférico das relações microfisicas entre e para além das instituições humanas. ${ }^{7}$ A inserção do discurso mais detidamente no plano institucional. todavia, coube ao exame em Pragmática, uma vez apoiada nos modelos do direito (contrato social entre emissão. contexto e recepção legítimos), do teatro (papéis sociais) e do jogo (regras sociais constitutivas). ${ }^{8}$ Mas o paralelismo traçado até aqui entre Análise do Discurso e Pragmática desfaz-se, contudo, no que concerne a um elemento inerente às condições de produção do discurso: a intenção de comunicar através da linguagem. O mesmo equivale a dizer que. no 
âmbito da Análise do Discurso, não é possível falar em intencionalidade do sujeito. Isto, porque este não é um indivíduo preexistente ao discurso que pretende enunciar, mas um "lugar", uma instância vazia, somente preenchida depois que um individuo é interpelado a assumir uma identidade (uma posição enunciativa nem sempre coincidente com seu papel na esfera social) a partir de sua enunciação que, portanto, o constitui enquanto o assujeita. Pelo viés da Pragmática o sujeito falante é eminente e preexiste ao campo social, cujas "condições de felicidade" circunstâncias pragmáticas como: emissão, contexto e recepção legítimos - viabilizam a comunicação e a realização bem sucedida dos atos de fala.

Neste momento da reflexão não há como discordar de Dominique Maingueneau, em Novas tendências em análise do discurso, para o qual a Análise do Discurso "é, com freqüência, reticente em relação à pragmática, por apresentar certas incompatibilidades no que tange aos seus próprios pressupostos teóricos. A dificuldade gira essencialmente em torno da questão da subjetividade enunciativa: muitos trabalhos de inspiração pragmática repousam sobre as 'intenções' de falantes cuja consciência seria transparente e a identidade estável, ultrapassando os diversos 'papéis' que desempenham."

\section{III - Foucault e a linguagem: uma análise pragmática do discurso}

Uma análise foucaultiana do discurso, certamente, consiste na apreensão da linguagem em uso como um ato. Mas esta é talvez a única semelhança patente com a abordagem da Pragmática, uma vez que nem a intenção de comunicar nem a predeterminação e exclusividade do campo social são levadas em conta na obra do filósofo francês. Especialmente se, à maneira de Foucault, compreendermos o discurso como um ato que é efeito de relações de forças inconscientes e, ao mesmo tempo, o elemento constitutivo de cada formação discursiva, produtor de novas expectativas sociais, as quais configuram estados de coisas de um novo campo discursivo.

Compreender o discurso como um ato que é efeito de relações de forças inconscientes é tomá-lo como um ato sem (para além do) sujeito. Este não é estudado por Foucault como fazem os integrantes da Pragmática, isto é, nem como sujeito que comunica nem como indivíduo ou coletividade social. O discurso como ato, embora advenha de uma instân- 
cia vazia (sujeito) quando um individuo assume uma posição enunciativa (uma identidade), não pode ser localizado absolutamente como ato do sujeito, mas de uma série de fatores correlatos com o saber e o poder em questão. Por conseguinte, além de não supor um sujeito, o discurso como ato autônomo também não supõe um sentido absoluto, localizável. É assim que o discurso sobre a mulher, por exemplo, em conformidade com os aspectos de épocas diversas, ora a põe como submissa e mantenedora do lar; ora como alguém que pode estudar, trabalhar. decidir ter ou não filhos etc.. Podemos dizer que o saber sobre a mulher foi engendrado por formações de campos discursivos que a concernem de tal ou qual modo, antes e depois do feudalismo, da expansão comercial, do capitalismo, das duas guerras mundiais. Nunca poderemos, entretanto. definir um ponto preciso que assegure o sentido dado, muito menos um responsável pelo discurso (ato) que constitua a mulher ocidental em nosso exemplo.

Acerca da vacuidade do sentido, Foucault assevera: "a análise do discurso, assim entendida, não desvenda a universalidade de um sentido; ela mostra à luz do dia o jogo da rarefação imposta, com um poder fundamental de afirmação. Rarefação e afirmação, rarefação, enfim, da afirmação e não generosidade contínua do sentido, e não monarquia do significante."10 Mas o discurso como um ato é, além disso. o elemento constitutivo de cada formação discursiva, produtor de novas expectativas sociais, as quais configuram estados de coisas de um novo campo discursivo. Compreender o discurso como ato. indo além da perspectiva da Pragmática, é afirmar que ele não satisfaz expectativas sociais prévias nem reproduz ou representa estados de coisas. Além disso, ultrapassando a perspectiva da Análise do Discurso, aquela de Foucault postula que a linguagem em uso (o discurso) não dá visibilidade a uma verdade oculta sob uma ideologia, por exemplo, mas torna visivel, articula o mundo que nos é dado a ver e para o qual, esquecendo esse momento, passamos a olhar com naturalidade, como se fosse desde sempre assim e não submetido ao devir histórico. Não é por menos que no século XIX os visionários medievais seriam classificados como loucos e confinados. enquanto em nosso século são ditos individuos reintegráveis à sociedade. Antes da Idade Média, seguramente, esses "comportamentos desviantes" para os padrões científicos da normalidade posterior, não foram tornados visiveis (criados) como problemáticos. Foucault. em $A$ história da loucura, por exemplo, procura mostrar que uma certa 
objetivação da doença mental nasce junto com o olhar médico e que a loucura como sintoma torna visível a manifestação necessária e específica de um mal, na forma de um caso dotado de um histórico particular." Em termos foucaultianos, uma análise "pragmática" do discurso consistiria na apreensão da linguagem em uso como um ato, que cria e sustenta regimes de verdade inerentes a estados de coisas e expectativas sociais posteriores. Os publicitários, por exemplo, dedicam-se a produzir desejo de consumo ou a criar necessidades em seu público-alvo. São célebres os exemplos como a vontade de beber Coca-Cola, depois de anunciado o produto; de vestir jeans e camiseta como símbolos de rebeldia, após os filmes de James Dean; de falar como as personagens das novelas etc.. O discurso não é mais entendido, então, como documento (representação) da realidade e sim como monumento (construção) desta. Antes que exprimir acontecimentos, ele é o acontecimento. ${ }^{12}$

\section{Conclusão}

Entender o discurso como prática, pelo viés da Análise do Discurso, é apreendê-lo entre a langue e a parole, como linguagem em uso, assumida pelo sujeito que fala e conforme a gênese que a configura no mundo. É afirmar que o sujeito surge junto com o sentido, não o preexistindo com a intenção de comunicar algo através de um sistema fechado de signos como a língua. Também é pensar, de acordo com Foucault, que o discurso é formado pelo caráter lingüístico dos fatos de linguagem e por um jogo estratégico e polêmico, relativo à história dos domínios de saber correspondentes às práticas sociais. Igualmente, é considerá-lo como enunciado, portador de significação apenas em um contexto histórico-social e segundo o sujeito, que ocupa uma posição vazia na enunciação. É compreender o sujeito de discurso ou conhecimento como responsável por exercer uma posição enunciativa, em um mundo cujas instituições nascem com os discursos ou enunciados. Do mesmo modo, é conceber o sentido como efeito de relações de poder constituídas no contexto histórico-social, fabricando e mantendo um saber; antes que definir o sentido como mero efeito do enunciado de um sujeito ideológico ou como encobridor de qualquer verdade. Uma abordagem foucaultiana do discurso, assim, o considera como constituído, ao mesmo tempo, com a linguagem e a comunicação, à medida que gera e sustenta relações maiores (nucleares; sociais; institucionais) e menores (periféricas; de grupos exclusos; gestos; polissemias; não necessari- 
amente humanas). O discurso como prática social e sua gênese (condições de produção) fazem parte, enfim, de um campo discursivo - todos os dados históricos num certo intervalo de tempo - e de uma formação discursiva - todos os enunciados que se apresentam como pontos característicos de um saber.

As práticas sociais e atos de fala dizem respeito a um certo paralelismo entre Análise do Discurso e Pragmática. Ambas estudam a linguagem em uso e em seu aspecto social. com algumas especificidades. Quanto ao uso. a Análise do Discurso difere da Lingüistica, tomando a linguagem praticada pelo sujeito falante e desconsiderando as línguas como objetos formais ou sistemas de signos destacados do mundo. Enquanto a Pragmática difere do Positivismo Lógico, tratando a linguagem como a realização de atos de fala no contexto das línguas e desprezando uma língua ideal apoiada na representação de estados de coisas que assegurem o sentido. Em relação ao aspecto social. uma abordagem foucaultiana da Análise do Discurso tenta inscrever a linguagem em uso pelo sujeito (o discurso) no plano periférico das relações microfisicas entre e para além das instituições humanas. Por outro lado, a Pragmática é marcada pela inserção do discurso no plano institucional, com base em modelos do direito (contrato entre emissão, contexto e recepção legitimos), do teatro (papéis sociais) e do jogo (regras sociais constitutivas). Mas. a intenção de comunicar através da linguagem. inerente às condições de produção do discurso. é o ponto de divergência entre a Análise do Discurso e a Pragmática. A Análise do Discurso não observa a intencionalidade do sujeito, porque este não é um indivíduo preexistente ao discurso que enunciará, mas um "lugar". uma instância vazia, preenchida só depois que um individuo é chamado a assumir uma identidade (posição enunciativa nem sempre idêntica a seu papel social), de maneira que sua enunciação, simultaneamente. o constitui e o assujeita. A Pragmática, por seu turno, supõe a intencionalidade do sujeito falante, o qual é eminente e preexiste à esfera social. cujas circunstâncias pragmáticas (emissores, contexto e receptores legítimos) tornam viável a execução bem sucedida dos atos de fala e a comunicação.

Uma análise pragmática do discurso corresponde à apreensão do discurso como prática, ou à linguagem $\mathrm{cm}$ uso como uma cspécie de ato. No interior destas considerações apoiadas no pensamento de Foucault. ultrapassando a perspectiva da Pragmática. o discurso não supõe a 
intencionalidade do sujeito, uma vez que é de natureza histórica e inconsciente e não se associa à predeterminação nem à exclusividade da esfera social. Este discurso como ato é efeito de relações de forças inconscientes, ou seja, um ato sem (para além do) sujeito, já que não pode ser localizado absolutamente como ato do sujeito, pois decorre de fatores correlacionados ao saber e ao poder em questão. Como ato autônomo, o discurso não supõe também um sentido absoluto, localizável, objetivo, dado naturalmente. O discurso como ato é, além disso, aquilo que constitui cada formação discursiva e produz expectativas sociais novas que circunscrevem estados de coisas de um campo discursivo novo. Indo além da perspectiva da Pragmática, o discurso como ato (prática social) não satisfaz expectativas sociais prévias de forma a representar ou reproduzir, de fato, estados de coisas. Indo além da perspectiva da Análise do Discurso, o discurso como ato (prática de instauração em sentido amplo) não dá visibilidade a uma verdade encoberta por uma ideologia, tornando visível (articulando) a realidade que nos é dada a ver e para a qual lançamos nosso olhar, projetando-a como natural, sem considerarmos o seu devir histórico ou o momento de sua instauração.

O discurso, a linguagem em uso como uma espécie de ato produtor, a prática discursiva social, enfim, possui o poder de criar e sustentar regimes de verdade relacionados a posteriores estados de coisas e expectativas sociais. Antes que documentar a realidade (representacionalismo), a prática discursiva social a edifica (construtivismo). Em outras palavras, sob a análise pragmática aqui explanada, o discurso é muito mais um acontecimento que uma expressão deste.

\section{Notas}

1 Hak, T. \& Gadet, F. (orgs.). Por uma Análise Automática do Discurso. Uma Introdução à Obra de Michel Pêcheux. São Paulo: UNIĊAMP, 1969. Pp. 13-38.

${ }^{2}$ A definição foucaultiana do discurso pode ser encontrada na Conferência 1, realizada pelo filósofo na PUC, entre 21 e 25/05/73:

"Há alguns anos foi original e importante dizer e mostrar que o que era feito com a linguagem - poesia, literatura, filosofia, discurso em ge- 
ral - obedecia a um certo número de leis ou regularidades internas - as leis e regularidades da linguagem. O caráter lingüístico dos fatos de linguagem foi uma descoberta que teve importância em determinada época.

Teria então chegado o momento de considerar esses fatos de discurso, não mais simplesmente sob seu aspecto lingüistico, mas, de certa forma - e aqui me inspiro nas pesquisas realizadas pelos anglo-americanos - como jogos (games), jogos estratégicos, de ação e de reação, de pergunta e de resposta, de dominação e de esquiva, como também de luta. O discurso é esse conjunto regular de fatos linguísticos em determinado nível, e polêmicos e estratégicos em outro (...)" - Cf. Foucault, Michel. A verdade e as formas juridicas. Rio de Janeiro: Nau Editora, 1996. p. 9.

'A crítica de Foucault à ideologia como o ocultamento de uma suposta verdade objetiva, dada naturalmente, fica patente na chamada "fase arqueológica do saber", com a eliminação do binômio ciência/ideologia em sua obra. Esta fase prima pelo exame do discurso como um todo simultaneamente presente, contextual (sincrônico), com suas modificações históricas, sucessivamente no tempo (diacrônicas). Nas palavras do próprio Foucault:

"...as condições políticas, econômicas de existência não são um véu ou um obstáculo para o sujeito de conhecimento mas aquilo através do que se formam os sujeitos de conhecimento e, por conseguinte, as relações de verdade. Só pode haver certos tipos de sujeito de conhecimento, certas ordens de verdade, certos domínios de saber a partir de condições políticas que são o solo em que se formam o sujeito, os domínios de saber e as relações com a verdade. Só se desembaraçando destes grandes temas do sujeito de conhecimento, ao mesmo tempo originário e absoluto, utilizando eventualmente o modelo nietzscheano, poderemos fazer uma história da verdade." (Foucault, Michel, op. cit., p. 27).

${ }^{4}$ Quanto às considerações de Pêcheux sobre Althusser, cf. "Sujeito, discurso e ideologia." in Hak, T. \& Gadet, F. (orgs.), op. cit., p. 30-34.

${ }^{5}$ Quanto à relação saber-poder, que se estabelece em meio a formações e campos discursivos, a seguinte afirmação de Foucault se faz condizente: "Tem-se o hábito de ver na fecundidade de um autor, na multiplicidade dos comentários, no desenvolvimento de uma disciplina, como que recursos infinitos para a criação dos discursos. Pode ser, mas não deixam de ser princípios de coerção; e é provável que não se possa 
explicar seu papel positivo e multiplicador, se não se levar em consideração sua função restritiva e coercitiva." (Foucault, Michel. A ordem do discurso. São Paulo: Loyola, 1996. Pp. 36). Aqui, o filósofo desloca a referência da noção de indivíduo psicológico (autor/intérprete) para a noção de sujeito (produtor/assujeitado), cuja natureza é da ordem do discurso, que o constitui ao mesmo tempo em que é constituído.

${ }^{6}$ Hak, T. \& Gadet, F. (orgs.), op. cit.

${ }^{7}$ Para uma distinção mais detalhada entre as duas temáticas, cf. Austin, J. L. Quand dire, c'est faire. Paris: Seuil, 1970.

${ }^{8}$ Esse alargamento das considerações de Foucault sobre o discurso além do plano institucional é, como segue, evidenciado pelo próprio filósofo: "O desejo diz: "Eu não queria ter de entrar nesta ordem arriscada do discurso; não queria ter de me haver com o que tem de categórico e decisivo; gostaria que fosse ao meu redor como uma transparência calma, profunda, indefinidamente aberta, em que os outros respondessem à minha expectativa, e de onde as verdades se elevassem, uma a uma; eu não teria senão de me deixar levar, nela e por ela, como um destroço feliz.' E a instituição responde: 'Você não tem por que temer começar; estamos todos aí para the mostrar que o discurso está na ordem das leis; que há muito tempo se cuida de sua aparição; que lhe foi preparado um lugar que o honra mas o desarma; e que, se lhe ocorre ter algum poder, é de nós, só de nós, que ele lhe advém.'

Mas pode ser que essa instituição e esse desejo não sejam outra coisa senão duas réplicas opostas a uma mesma inquietação: inquietação diante do que é o discurso em sua realidade material de coisa pronunciada ou escrita; inquietação diante dessa existência transitória 
destinada a se apagar sem dúvida, mas segundo uma duração que não nos pertence; inquietação de sentir sob essa atividade, todavia cotidiana e cinzenta, poderes e perigos que mal se imagina; inquietação de supor lutas, vitórias, ferimentos, dominações, servidões, através de tantas palavras cujo uso há tanto tempo reduziu as asperidades." (Foucault, Michel. A ordem do discurso. São Paulo: Loyola, 1996. Pp. 7-8).

${ }^{9}$ Sobre a inserção do discurso no plano institucional, exposta em Pragmática, o seguinte trecho mostra-se pertinente: "Durante muito tempo a $\mathrm{AD}$ tomou como objeto os corpus por ela apreendidos independentemente dos atos de enunciação que os haviam tornado possíveis. Ao proceder assim, não tinha o intuito de negligenciar as "circunstâncias', o 'quadro' de enunciação, mas por entender tais fatos mais como um conjunto de elementos moduladores do que como uma dimensão constitutiva do discurso. Atesta esta situação a maneira como era utilizada a noção de instituição: se a língua era reconhecida como uma instituição, o mesmo não ocorria com o discurso. É sobretudo através das questões dos atos de fala que uma concepção diferente emergiu. Apoiando-se em modelos emprestados do direito, do teatro ou do jogo, a pragmática tentou inscrever a atividade da linguagem em espaços institucionais." (Maingueneau, Dominique. Novas tendências em análise do discurso. Campinas, SP: Pontes/UNICAMP, 1989. P. 29).

${ }^{10}$ Maingueneau, D., op. cit., p. 32._Foucault, Michel. A ordem do discurso. São Paulo: Loyola, 1996. P. 70.

"Cf. Foucault, Michel. A história da loucura. São Paulo: Perspectiva, 1978. A propósito da crença no poder de explicação e classificação da ciência, que associada à política pode conduzir o homem a afastar-se de outros indivíduos singulares, Machado de Assis mostra, em O Alienista, como a ciência revela o não sentido da mente humana e do funcionamento da sociedade.

Simão Bacamarte - a personagem principal que encorpora o espírito científico e cuja ambição era erradicar a loucura de Itaguai e do mundo a título de caridade - busca e não consegue um critério para enquadrar a loucura; a ponto de internar radicalmente o povo da vila quase inteira, soltá-lo e, por fim, internar-se a si mesmo.

No conto de Machado, a loucura e a sanidade fluem ao sabor das relações afetivas, sociais e políticas envolvidas: 
"Três dias depois, numa expansão intima com o boticário Crispim Soares, desvendou o alienista o mistério do seu coração.

- A caridade, Sr. Soares, entra decerto no meu procedimento, mas entra como tempero, como o sal das coisas, que é assim que interpreto o dito de S. Paulo aos Coríntios: 'Se eu conhecer quanto se pode saber, e não tiver caridade, não sou nada'. O principal nesta minha obra da Casa Verde é estudar profundamente a loucura, os seus diversos graus, classificar-lhe os casos, descobrir enfim a causa do fenômeno e o remédio universal. Este é o mistério do meu coração. Creio que com isto presto um bom serviço à humanidade.

(...) Dentro de cinco dias, o alienista meteu na Casa Verde cerca de cinqüenta aclamadores do novo governo. (...)

(...) Daí em diante foi uma coleta desenfreada. Um homem não podia dar nascença ou curso à mais simples mentira do mundo, ainda daquelas que aproveitam ao inventor ou divulgador, que não fosse logo metido na Casa Verde. Tudo era loucura. Os cultores de enigmas, os fabricantes de charadas, de anagramas, os maldizentes, os curiosos da vida alheia, os que põem todo o seu cuidado na tafularia, um ou outro almotacé enfunado, ninguém escapava aos emissários do alienista. (...)

(...) E agora prepare-se o leitor para o mesmo assombro em que ficou a vila, ao saber um dia que os loucos da Casa Verde iam todos ser postos na rua.

(...) Fechada a porta da Casa Verde, entregou-se ao estudo e à cura de si mesmo. Dizem os cronistas que ele morreu dali a dezessete meses, no mesmo estado em que entrou, sem ter podido alcançar nada. Alguns chegam ao ponto de conjeturar que nunca houve outro louco, além dele, em Itaguai; mas esta opinião, fundada em um boato que correu desde que o alienista expirou, não tem outra prova, senão 0 boato; e boato duvidoso, pois é atribuído ao padre Lopes, que com tanto fogo realçara as qualidades do grande homem. Seja como for, efetuou-se o enterro com muita pompa e rara solenidade." - Cf. "O alienista" in Alves, Roberto (seleção e apresentação). Contos escolhidos. Rio de Janeiro: Klick/O Globo, s.d. (Col. Livros-17). Pp. 42, $72,74,76$ e 86. 
12 No que diz respeito à concepção contemporânea do discurso, Foucault assinala: "Há, sem dúvida, em nossa sociedade e, imagino, em todas as outras mas segundo um perfil e facetas diferentes, uma profunda logofobia, uma espécie de temor surdo desses acontecimenlos, dessa massa de coisas ditas, do surgir de todos esses enunciados, de tudo o que possa haver ai de violento, de descontínuo, de combativo, de desordem, também, e de perigoso, desse grande zumbido incessante e desordenado do discurso.

E se quisermos, não digo apagar esse temor, mas analisá-lo em suas condições, seu jogo e seus efeitos, é preciso, creio, optar por três decisões às quais nosso pensamento resiste um pouco. hoje em dia, e que correspondem aos três grupos de funções que acabo de evocar: questionar nossa vontade de verdade; restituir ao discurso seu caráter de acontecimento; suspender, enfim, a soberania do significante." (Foucault, Michel. A ordem do discurso. São Paulo: Loyola, 1996. p. 50-51).

\section{Bibliografia}

ALVES, Roberto (seleção e apresentação). Contos escolhidos. Rio de Janeiro: Klick/O Globo, s. d. (Col. Livros-17).

AUSTIN, J. L. Quand dire c'est faire. Paris: Seuil, 1970.

FOUCAULT, Michel. A história da loucura. São Paulo: Perspectiva, 1978.

1996.

A ordem do discurso. São Paulo: Loyola,

A verdade $e$ as formas juridicas. Rio de Janeiro: Nau Editora, 1996.

HAK, T. \& GADET, F. (orgs.). Por uma análise automática do discurso. Uma introdução à obra de Michel Pêcheux. São Paulo: UNICAMP, 1969.

MAINGUENEAU, Dominique. Novas tendências em análise do discurso. Campinas, SP: Pontes/UNICAMP, 1989. 


A revista contracampo permanece fiel ao propósito de estabelecer aberto diálogo entre as mais diferentes abordagens nos campos da comunicação contemporânea, conformando assim o necessário espaço para os debates transdisciplinares.
Neste terceiro número, a novidade maior fica por conta do início da publicação de artiǵos de alunos, o que representa passo decisivo para a completa integração dos corpos docente e discente do curso de Mestrado em Comunicação, Imagem e Informação da Universidade Federal Fluminense. 